\title{
Analisis Potensi Ekowisata dan Kesiapan Masyarakat Desa Rendu Tutubadha dalam Pengembangan Ekowisata
}

Adriano Filemon Ajaa,1, I Nyoman Sukma Aridaa,2

1 ajaandriano@gmail.com, ${ }^{2}$ sukma_arida@unud.ac.id

a Program Studi Sarjana Destinasi Pariwisata, Fakultas Pariwisata, Universitas Udayana, JL. Dr. R. Goris, Denpasar, Bali 80232 indonesia

\begin{abstract}
Tourism trend and tourist motivation changes dynamically since the first time development of tourism. Mass tourism is one of tourism trend which grow Praccessibility, etc) and tour with a big group. Ecotourism appears in the early of 1990, ecotourism can be defined as a responsibility journey to a natural place. The aim is to make empowerement in the local society, conservancy, and the preservation of local society's culture. Ecotourism grows fastly because this trend is different from conventional tourism which dominates. Rendu Tutubadha village locates in Aesesa District, Nagekeo Regency, East Nusa Tenggara Province has a big potential of ecotourism. Ecotourism potentials in this village consists of natural hot spring of Ae Petu Meze, Lambo Mountain, traditional village and etu ritual. Develop these ecotourism potentials needs readiness of Rendu Tutubadha's society so the development will hold by the ecotourism principals and give positive effect to the society in eceonomis and other aspect. This research using primary and secondary data, quantitative and qualitative data is also used in this research. Data collecting method is interview, literature study, and observation. Qualitative descriptive used to presents the research result. This research finds some ecotourism potenstials in Rendu Tutubadha village. The ecotourism potential is nature and culture potential. The nature potential is like natural hot spring of Ae Petu Meze and Lambo Mountain, besides of that there are two culture potentials like traditional village of Rendu Tutubadha and Etu ritual. This research also finds that Rendu Tutubadha's society readiness is enough to develop ecotourism, it can be seen in the society's traditional life, although there are some aspects of ecotourism needs to fixed
\end{abstract}

Keyword: ecotourism potential, ecotourism, society readiness

\section{PENDAHULUAN}

Kepariwisataan berkembang dengan dinamis sejak awal kemunculannya. Berbagai macam tren wisata telah banyak bermunculan dan memenuhi motivasi wisatawan yang beragam. Tren-tren wisata berkembang seiring dengan motivasi wisatawan yang juga terus berkembang. Pariwisata masal merupakan salah satu tren yang telah berkembang dengan ciri di mana wisatawan melakukan perjalanan secara berkelompok dan memanfaatkan fasilitas seperti akomodasi atau fasilitas lain yang telah disesuaikan dengan kondisi di daerah asal wisatawan. Tren pariwisata masal kurang memperhatikan dan memanfaatkan potensi-potensi lokal dan bila dimanfaatkan cenderung diubah untuk disesuaikan dengan kemauan wisatawan. Kepariwisataan yang terus bergerak dinamis juga sejalan dengan perubahan dalam kehidupan sosial budaya masyarakat lokal yang menjadi tuan rumah. Kesiapan masyarakat dalam pengembangan kepariwisataan seringkali tidak terlalu diperhitungkan dan akhirnya membawa dampak negatif.

Sebuah tren baru berkembang di kalangan wisatawan setelah perkembangan wisata masal. Tren baru tersebut adalah perjalanan ke area alami yang bertujuan untuk konservasi sumber daya alam atau yang biasa disebut ekowisata. Tren ini muncul karena motivasi wisatawan yang mulai berubah seiring dengan perkembangan pariwisata masal yang sangat massif melalui komersialisasi dan komodifikasi.

Desa Rendu Tutubadha yang terletak di Kabupaten Nagekeo, Provinsi NTT merupakan desa yang memiliki banyak potensi. Potensi wisata di desa ini terdiri dari potensi wisata alam dan budaya seperti desa adat, sumber air panas alami atau gunung. Potensi-potensi ini cocok untuk dikembangkan untuk menjadi ekowisata. Kehidupan masyarakat di desa adat yang relatif masih tradisional dan keunikan bentang alam seperti sumber air panas dapat menjadi alternatif bagi wisatawan yang jenuh dengan suasana perkotaan atau wisata-wisata konvensional. Apalagi kemudahan akses ke Desa Rendu Tutubadaha didukung dengan jalan beraspal dan jarak yang tidak terlalu jauh dari ibukota kabupaten. Potensi-potesi yang ada di Desa Rendu Tutubadha berpeluang untuk dijadikan sebagai ekowisata. Peluang ini harus diimbangi dengan kesiapan masyarakat untuk menjalankan ekowisata sesuai dengan prinsipprinsip ekowisata. Kesiapan masyarakat yang tampak dalam partisipasi masyarakat akan berujung pada 
Vol. 8 No 2, 2020

pengembangan ekowisata yang sesuai dan memberikan manfaat yang baik untuk masyarakat sendiri.

Potensi-potensi yang dimiliki ini dipandang perlu oleh peneliti untuk didata dan dikemas agar dapat dikembangkan sebagai daya Tarik wisata. Apalagi tren wisata saat ini yang cenderung mengarah kepada ekowisata merupakan peluang yang harus dimanfaatkan dengan memanfaatkan dan mengembangkan semua potensi-potensi yang ada. Selain itu kesiapan masyarakat Desa Rendu Tut5utbadha juga menjadi hal yang penting untuk ditekiti agar bisa melihat sejauh mana masyarakat siap unyuk mengembangkan ekowisata.

\section{METODE}

Penelitian ini dilakukan di Desa Rendu Tutubadha, Kabupaten Nagekeo, Provinsi Nusa Tenggara Timur. Penelitian ini dilakukan untuk menemukan potensi-potensi ekowisata yang ada di Desa Rendu Tutubadha. Selain itu untuk meneliti kesiapan masyarakat dalam menerapkan ekowisata. Ruang lingkup permasalahan dalam penelitian ini adalah potensi wisata yang berupa alam dan budaya, kesiapan masyarakat Desa Rendu Tutubadha. Teknik pengumpulan data dalam penelitian ini yaitu wawancara (Suryawan, dkk., 2017), observasi (Moleong, 1991) dan studi kepustakaan (Sugiyono, 2014). Tujuan dari penelitian ini adalah mengetahui potensi ekowisata yang ada di Desa Rendu Tutubadha dan kesiapan masyarakat dalam menerapkan ekowisata. Metode analisis data dalam penelitian ini yaitu dengan mengatur urutan data, mengorganisasikannya ke dalam suatu pola, kategori, dan satuaan uraian dasar (Patton,1980).

\section{PEMBAHASAN DAN HASIL}

\subsection{Potensi Ekowisata di Desa Rendu Tutubadha}

\subsubsection{Air Panas Ae Petu Meze}

Sumber air panas alami ae petu Meze merupakan sebuah mata air alami yang mengeluarkan air panas. Sumber air yang keluar dari tebing ini membentuk kolam yang cukup besar di bawahnya, karena alasan inilah sumber air panas ini dinamakan ae petu meze, ae berarti air, petu berarti panas, dan meze berarti besar oleh masyarakat setempat. Jarak sumber air panas ini dari jalan utama $1.5 \mathrm{~km}$. Jalan menuju sumber air panas ini masih merupakan jalan tanah dengan beberapa bagian yang masih terjal karena topografi yang berbukit-bukit.

Sepanjang perjalanan padang savana luas mendominasi pemandangan, selain itu ada juga Gunung Kalilambo dan perbukitan serta pemandangan Kota Mbay di kejauhan. Area yang masih alami dan minim pembangunan disekitarnya menyediakan interpretasi bagi wisatawan untuk lebih mencintai alam. Secara tidak langsung kondisi alam yang masih asri dan terjaga akan menyadarkan wisatawan bahwa alam yang tidak dieksplotasi dan dijaga akan menawarkan keindahan dan memberikan keuntungan. Secara umum atraksi yang ditawarkan di sumber air panas ini yaitu mandi di kolam air panas atau menikmati pemandangan alam. Aksesibilitas menuju ke sumber air panas ini ditunjang dengan jalan beraspal yang menghubungkan Desa Rendu Tutubadha dan Kota Mbay, sedangkan untuk akses menuju sumber air panas dari jalan utama masih berupa jalan tanah yang akan berlumpur dan becek di musim hujan di musim hujan.

Kelompok sadar wisata Desa Rendu Tutubadha selaku otoritas atau lembaga yang memegang peranan dalam penyediaan fasilitas di daya tarik wisata ini belum melakukan pembenahan fasilitas atau aksesibilitas karena kendala dan dana serta dasar hukum atau surat keputusan penetapan Desa Rendu Tutubadha sebagai desa wisata yang masih simpang siur. Dinas Pariwisata Kabupaten Nagekeo telah melakukan survey lokasi bersama dengan kelompok sadar wisata, tetapi belum ada tindak lanjut dari hasil survey seperti pembenahan fasilitas dan aksesibilitas atau promosi. Sumber air panas ini tergolong tempat yang masih sangat terisolasi dan belum banyak diketahui oleh masyarakat luas.

\subsubsection{Gunung Lambo}

Gunung Lambo adalah sebuah gunung dengan ketinggian \pm 1500 mdpl. Gunung ini merupakan gunung yang cukup unik karena memililiki tiga puncak. Gunung ini memiliki karakteristik dengan ciri hutan hujan tropis yang masih sangat alami karena minim eksploitasi. Di sebelah barat gunung ini juga terdapat savana luas dan sebuah air terjun dengan tinggi sekitar 80 meter. Gunung Kalilambo menawarkan lingkungan alami yang sangat potensial untuk dikembangkan menjadi ekowisata. Kondisi hutan yang masih alami juga menjadi habitat dari satwa-satwa liar. Atraksi yang ditawarkan adalah pendakian gunung dan penjelajahan hutan yang bisa dikombinasikan dengan perjalanan ke air terjun di Desa Rendu Butowe setelah pendakian selesai. Aksesibilitas menuju kawasan gunung ini dilakukan dengan berjalan kaki. Fasilitas penunjang seperti pos pendakian belum tersedia dan jalur pendakian yang bisa dilalui merupakan jalur yang sering dimanfaatkan masyarakat. Potensi Gunung Lambo ini juga belum mendapat perhatian dari kelompok sadar wisata karena wisata minat khusus pendakian gunung yang terbilang masih belum terlalu populer di kalangan wisatawan lokal. 


\subsubsection{Ritual Etu}

Ritual Etu atau tinju adat merupakan ritual yang rutin dilaksanakan oleh masyarakat Desa Rendu Tutubadha setiap tahun pada bulan Juni-Juli. Pelaksanaan ritual etu terbagi dalam beberapa rangkaian ritual penting lainnya yang dilaksanakan satu minggu sebelumnya. Rangkaian ritual ini merupakan bagian yang tidak dapat dipisahkan dari kagiatan menanam dan memanen yang dilakukan oleh masyarakat. Pelaksanaa ritual ini merupakan bentuk terima kasih kepada bumi yang telah memberikan hasil panen kepada masyarakat. Ritual tinju ini berbeda dengan tinju konvensional, mulai dari peraturan sampai dengan peralatan yang digunakan. Dalam ritual ini pemuda-pemuda yang ingin bertinju akan dimasukkan ke dalam arenatinju setelah dipilih oleh wasit yang disebut sike. Di badan petinju akan diikatkan selendang tradisional yang digunakan sike untuk menarik petinju apabila kompetisi berjalan tidak kondusif. Jumlah ronde dalam tinju adat juga tidak ditentukan secara pasti, tinju akan berhenti apabila salah satu petinju menyerah atau terluka. Seorang petinju akan dibekali dengan sebuah alat yang dalam bahasa setempat disebut kepo, alat ini merupakan anyaman dari ijuk yang digunakan untuk melukai lawan. Petinju hanya boleh menggunakan satu kepo dan satu tangan untuk bertinju, sedangkan tangan yang lainnya digunakan untuk menangkis serangan

\subsubsection{Perkampungan Tradisional Desa Rendu Tutubadha}

Di dalam wilayah Desa Rendu Tutubadha terdapat sebuah kompleks perkampungan tradisional yang masih menjaga keaslian bangunan. Kompleks perkampungan tradisional ini terpisah dari pemukiman lainnya yang didominasi bangunan konvensional. Bangunan rumah di dalam kompleks kampung tradisional ini dibangun dengan memanfaatkan material yang langsung diambil dari alam seperti kayu pohon lontar untuk tiang rumah, rumput kering sebagai atap dan sebagai penyambung dan pengikat dimanfaatkan tali yang dibuat dari serat-serat pohon. Bapak Zakarias Sela Nima, salah seorang tetua di Desa Rendu Tutubadha menyatakan bahwa ada aturan adat yang melarang untuk memanfaatkan bahan-bahan bangunan modern seperti seng untuk membangun rumah di dalam kompleks ini. Rumah-rumah di dalam kompleks perkampungan ini azim disebut sa'o ji vao. sa'o artinya rumah, $j i$ artinya kekuatan dan vao artinya naungan. setiap rumah juga memiliki nama masingmasing seperti rumah Bapak Zakarias (narasumber) yang diberi nama dara tuka. Pemberian nama kepada rumah ini sesuai dengan filosofi masing- masing penghuninya.

Perkampungan inilah yang menjadi lokasi diadakannya ritual etu atau tinju adat setiap tahunnya. Selain bangunan rumah adat dan ritual etu yang menjadi daya tarik, di halaman tengah kompleks perkampungan ini juga terdapat kuburan pahlawan perang dari masa lampau yang tebuat dari batu dan beberapa ritual adat lainnya seperti potong kerbau (para bhada) atau sunat (tau nuwa). Atraksi lain yang ditawarkan oleh perkampungan tradisional ini adalah melihat rumah adat dan ritual adat serta keseharian masyarakat lokal seperti menenun atau berkebun.

Desa ini memiliki aksesibilitas yang bagus karena desa ini terletak tepat di pinnggir jalan raya. Fasilitas penunjang di desa ini terdiri dari gapura yang terletak di pintu masuk desa dan area parkir. Desa ini juga memiliki keuntungan karena mendapat banyak perhatian dari kelompok sadar wisata karena letaknya yang mudah dijangkau dan dekat dengan pemukiman. Operasional di perkampungan tradisional juga telah dikembangkan dengan sistem donasi, setiap wisatawan yang datang sendiri atau spontan tidak dikenakan biaya khusus, tetapi donasi. Sedangkan wisatawan yang datang dalam rombongan atau grup akan dikenakan biaya sebesar Rp 1.200 .000 /grup. Wisatawan yang dalam rombongan atau yang sudah membuat janji dengan kelompok sadar wisata akan disambut dengan tarian dan dipakaikan selendang atau pakaian adat sesuai dengan permintaan wisatawan. Selain itu wisatawan yang datang dalam rombongan juga akan disajikan makanan sesuai dengan kesepakatan pada saat janji dibuat.

\subsection{Kesiapan Masyarakat dalam Pengembangan Ekowisata}

Kesiapan masyarakat Desa Rendu

Tutubadha dalam mengembangkan ekowisata dianalisis dengan menggunakan the international ecotourism standard. Hasil analisis dapat dilihat di tabel berikut:

\begin{tabular}{|c|c|c|}
\hline No & Prinsip & Kondisi \\
\hline \multirow[t]{3}{*}{1} & \multicolumn{2}{|c|}{$\begin{array}{l}\text { Memiliki kepedulian, komitmen dan tanggung } \\
\text { jawab terhadap konservasi } \\
\text { alam dan warisan budaya }\end{array}$} \\
\hline & $\begin{array}{l}\text { Tercapainya } \\
\text { keseimbangan } \\
\text { pemanfaatan } \\
\text { lahan }\end{array}$ & \multirow{2}{*}{$\begin{array}{l}\text { Di Desa Rendu } \\
\text { Tutubadha dan desa- } \\
\text { desa lain di sekitar yang } \\
\text { masih tergabung } \\
\text { dalam satu suku ada } \\
\text { peraturan adat yang } \\
\text { melarang warga desa } \\
\text { untuk menjual tanah } \\
\text { mereka. Tanah yang ada } \\
\text { hanya boleh digunakan } \\
\text { untuk } \\
\text { membangun rumah atau } \\
\text { membuat kebun } \\
\text { dengan izin dari pemilik } \\
\text { tanah dan ukuran yang } \\
\text { telah } \\
\text { disesuaikan, misalnya } \\
\text { untuk membangun }\end{array}$} \\
\hline & & \\
\hline
\end{tabular}


Vol. 8 No 2, 2020

\begin{tabular}{|c|c|c|c|c|}
\hline & $\begin{array}{l}\text { rumah dialokasikan luas } \\
\text { sebesar } 30 \mathrm{~m} \text { x } 40 \mathrm{~m} . \\
\text { aturan ini jika } \\
\text { dipertahankan akan } \\
\text { menciptakan } \\
\text { keseimbangan lahan } \\
\text { dimana pemukiman dan } \\
\text { lahan pertanian } \\
\text { akan terus seimbang dan }\end{array}$ & & & $\begin{array}{l}\text { perburuan, tetapi } \\
\text { setelah itu dilarang } \\
\text { karena } \\
\text { memberikan dampk } \\
\text { buruk } \\
\text { kepada lingkungan dan } \\
\text { keanekaragaman } \\
\text { hayati }\end{array}$ \\
\hline \multirow{4}{*}{$\begin{array}{ll}\text { Penggunaan } & \\
\text { teknologi } & \text { ramah } \\
\text { lingkungan } & \end{array}$} & tidak berat sebelah. & & \multirow{2}{*}{$\begin{array}{l}\text { Memperhatikan } \\
\text { keberadaan } \\
\text { endemis }\end{array}$} & \multirow[b]{2}{*}{$\begin{array}{l}\text { Di Desa Rendu } \\
\text { Tutubadha tidak } \\
\text { terdapat tumbuhan atau } \\
\text { satwa endemis yang } \\
\text { perlu dilindungi }\end{array}$} \\
\hline & $\begin{array}{l}\text { Masyarakat Desa Rendu } \\
\text { Tutubadha sejauh ini } \\
\text { memanfaatkan } \\
\text { teknologi ramah }\end{array}$ & & & \\
\hline & $\begin{array}{l}\text { lingkungan seperti } \\
\text { Penggunaan pupuk } \\
\text { kimia yang dibatasi } \\
\text { untuk lahan pertanian. }\end{array}$ & \multirow[t]{5}{*}{2} & \multicolumn{2}{|c|}{$\begin{array}{l}\text { Menyediakan interpretasi yang memberikan } \\
\text { peluang kepada wisatawan untuk menikmati alam } \\
\text { dan meningkatkan kecintaanya terhadap alam }\end{array}$} \\
\hline & 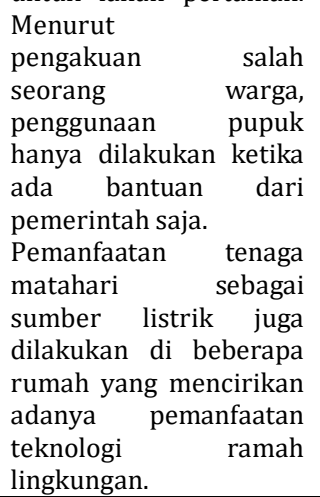 & & \multirow[t]{3}{*}{$\begin{array}{l}\text { Menyediakan } \\
\text { pramuwisata } \\
\text { profesional dan } \\
\text { berlisensi }\end{array}$} & \multirow{3}{*}{$\begin{array}{l}\text { Pramuwisata yang } \\
\text { tersedia di Desa Rendu } \\
\text { saat ini berjumah tiga } \\
\text { orang menurut } \\
\text { penuturan Bapak } \\
\text { Amandus Watu, Ketua } \\
\text { kelompok } \\
\text { sadar wisata Desa Rendu } \\
\text { Tutubadha. Tiga orang } \\
\text { pramuwisata ini } \\
\text { terdiri dari dua } \\
\text { orang pria dan satu } \\
\text { orang wanita. Tiga } \\
\text { orang pramuwisata ini } \\
\text { bertugas melayani } \\
\text { wisatawan asing } \\
\text { yang berkunjung ke } \\
\text { Desa Rendu Tutubadha. } \\
\text { Tiga orang pamuwisata } \\
\text { ini bisa berbahasa } \\
\text { Inggris dan telah } \\
\text { mendapat pelatihan } \\
\text { guiding dari Dinas } \\
\text { Pariwisata Kabupaten } \\
\text { Nagekeo }\end{array}$} \\
\hline $\begin{array}{l}\text { Pemanfaatan } \\
\text { areal warisan } \\
\text { budaya sebagai } \\
\text { objek ekowisata } \\
\text { disesuaikan } \\
\text { dengan daya } \\
\text { dukung }\end{array}$ & 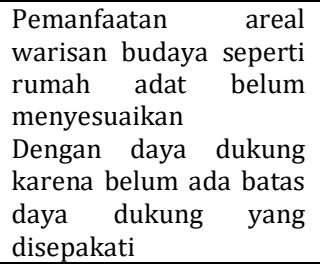 & & & \\
\hline \multirow[t]{2}{*}{$\begin{array}{l}\text { Melestarikan } \\
\text { keanekaragaman } \\
\text { hayati dan cagar } \\
\text { budaya }\end{array}$} & \multirow[b]{2}{*}{ 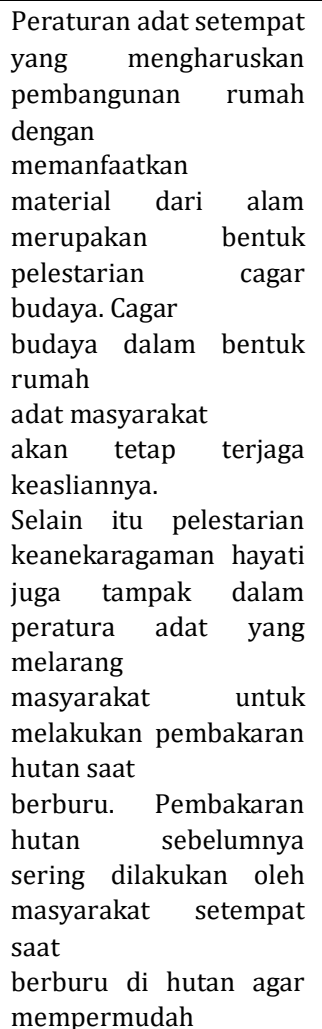 } & & & \\
\hline & & & $\begin{array}{l}\text { Menyediakan } \\
\text { fasilitas pendukung } \\
\text { dan informasi yang } \\
\text { memadai terkait } \\
\text { dengan objek } \\
\text { ekowisata }\end{array}$ & $\begin{array}{l}\text { Amandus Watu, } \\
\text { ketua kelompok } \\
\text { sadar wisata Desa } \\
\text { Rendu Tutubadha } \\
\text { menuturkan } \\
\text { bahwa } \\
\text { penyediaan } \\
\text { fasilitas masih } \\
\text { sulit dilakukan } \\
\text { karena tidak ada } \\
\text { partisipasi dari } \\
\text { langsung dalam } \\
\text { dinas dan dana, } \\
\text { tetapi debuah } \\
\text { waktu dekat akan } \\
\text { dibuat san } \\
\text { banner di gapura } \\
\text { perkampungan } \\
\text { tradisional yang } \\
\text { berisi tentang } \\
\text { informasi } \\
\text { perkampungan } \\
\text { tradisional Desa } \\
\text { Rendu } \\
\text { Tutubadha }\end{array}$ \\
\hline
\end{tabular}


Vol. 8 No 2, 2020

\begin{tabular}{|c|c|c|c|c|c|}
\hline & $\begin{array}{l}\text { Melibatkan lembaga } \\
\text { adat } \\
\text { setempat }\end{array}$ & $\begin{array}{l}\text { Pelibatan lembaga adat } \\
\text { hampir terjadi dalam } \\
\text { setiap kesempatan, } \\
\text { lembaga adat pun } \\
\text { dilibatkan dalam } \\
\text { struktur kepengurusan } \\
\text { kelompok sadar } \\
\text { wisata Desa } \\
\text { Rendu Tutubadha }\end{array}$ & & $\begin{array}{l}\text { nilai } \\
\text { sosial budaya dan } \\
\text { tradisi keagamaan } \\
\text { masyarakat } \\
\text { setempat }\end{array}$ & $\begin{array}{l}\text { Rendu Tutubadha } \\
\text { terbilang sangat } \\
\text { menghargai } \\
\text { kearifan lokal dan } \\
\text { norma adat, yang } \\
\text { paling tampak } \\
\text { terlihat di } \\
\text { perkampungan }\end{array}$ \\
\hline \multirow[t]{6}{*}{3} & \multicolumn{2}{|c|}{ 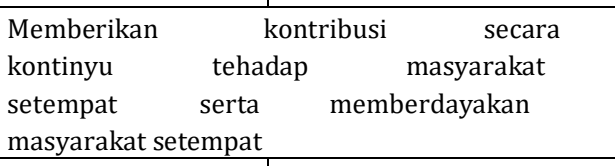 } & & & $\begin{array}{l}\text { Rendu Tutubadha } \\
\text { di } \\
\text { wisatawan }\end{array}$ \\
\hline & \multirow[t]{2}{*}{$\begin{array}{l}\text { Memprioritaskan } \\
\text { pemanfaatan tenaga } \\
\text { kerja lokal sesuai } \\
\text { dengan keahlian }\end{array}$} & \multirow[t]{2}{*}{ 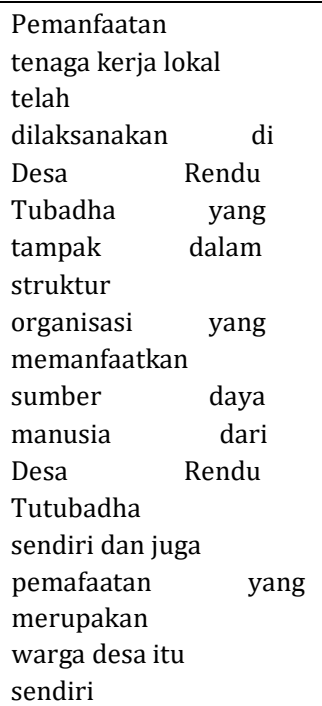 } & & & \begin{tabular}{lr}
$\begin{array}{l}\text { dipakaikan } \\
\text { selendang }\end{array}$ \\
tradisional & atau \\
pakaian & adat \\
sesuai & dengan \\
permintaan & \\
wisatawan. & Selain \\
itu & apabila \\
masuk & sampai ke \\
dalam & rumah \\
masyarakat, pemilik \\
\multicolumn{4}{c}{ rumah } \\
akan $\quad$ meminta \\
izin $\quad$ terlebih \\
dahulu kepada leluhur \\
dengan ritual singkat.
\end{tabular} \\
\hline & & & & $\begin{array}{l}\text { Keberadaan } \text { dan } \\
\text { kegiatan objek } \\
\text { ekowisata tidak } \\
\text { mengganggu aktivitas }\end{array}$ & \begin{tabular}{lrr}
\multicolumn{2}{l}{ Aktivitaswisata } & yang \\
terjadi & di & Desa \\
Rendu & Tutubadha \\
tidak & mengganggu
\end{tabular} \\
\hline & $\begin{array}{l}\text { Memprioritaskan } \\
\text { pemanfaatan } \\
\text { produk lokal } \\
\text { untuk } \\
\text { operasional } \\
\text { objek pariwisata }\end{array}$ & $\begin{array}{l}\text { Produk lokal } \\
\text { untuk operasional } \\
\text { objek pariwisata } \\
\text { tampak dalam } \\
\text { pemafaatan alat } \\
\text { musik tradisional } \\
\text { ketika } \\
\text { menyambut tamu, } \\
\text { juga beberapa } \\
\text { souvenir yang } \\
\text { dijual masyarakat } \\
\text { merupakan lokal } \\
\text { produk seperti kain tenun } \\
\text { dan an topi } \\
\text { anyaman }\end{array}$ & & $\begin{array}{l}\text { keagamaan } \\
\text { masyarakat setempat }\end{array}$ & $\begin{array}{l}\text { aktivitas keagamaan } \\
\text { masyarakat setempat } \\
\text { yang tampak dalam } \\
\text { operasional wisata. } \\
\text { Contohnya tarian- } \\
\text { tarian tertentu } \\
\text { hanya akan } \\
\text { dipentaskan sesuai } \\
\text { dengan waktunya } \\
\text { (kebutuhan adat), } \\
\text { tidak berdasarkan } \\
\text { permintaan sehingga } \\
\text { wisatawan sehan adanya } \\
\text { mencegah atau } \\
\text { komersialisasi atau } \\
\text { komodifikasi. Selain } \\
\text { itu peribadatan yang }\end{array}$ \\
\hline & \multirow[t]{3}{*}{$\begin{array}{l}\text { Melibatkan lembaga } \\
\text { adat setempat }\end{array}$} & \multirow{3}{*}{$\begin{array}{l}\text { Partisipasi } \\
\text { lembaga adat } \\
\text { tampak dalam } \\
\text { penyambutan } \\
\text { tamu yang dating } \\
\text { ke desa di mana } \\
\text { biasanya tamu } \\
\text { yang datang akan } \\
\text { disambut tarian } \\
\text { yang dikoordinir } \\
\text { oleh lembaga adat } \\
\text { setempat }\end{array}$} & & & $\begin{array}{lr}\text { dilangsunglan } & \text { di } \\
\text { dekat gereja } & \text { yang } \\
\text { berada di } & \text { dekat } \\
\text { perkampungan } & \\
\text { tradisional } & \text { berjalan } \\
\text { seperti } & \text { biasa } \\
\text { walaupun } & \text { ada } \\
\text { rombongan } & \\
\text { wisatawan yang } \\
\text { berkunjung. } \\
\end{array}$ \\
\hline & & & \multirow[t]{4}{*}{5} & \multicolumn{2}{|c|}{$\begin{array}{l}\text { Menaati peraturan } \\
\text { undangan yang berlaku }\end{array}$} \\
\hline & & & & Menaati undang- & pengambilan \\
\hline \multirow[t]{2}{*}{4} & \multicolumn{2}{|c|}{$\begin{array}{l}\text { Peka dan menghormati nilai-nilai } \\
\text { sosial budaya dan tradisi keagamaan } \\
\text { masyarakat setempat }\end{array}$} & & $\begin{array}{l}\text { undang dan } \\
\text { perangkat peraturan } \\
\text { lainnya yang }\end{array}$ & $\begin{array}{l}\text { keputusan seperti } \\
\text { yang dituturkan } \\
\text { ketua pokdarwis }\end{array}$ \\
\hline & $\begin{array}{lr}\text { Peka } & \text { dan } \\
\text { menghormati } & \text { nilai- } \\
\end{array}$ & \begin{tabular}{l}
\multicolumn{3}{|l|}{ Operasional } \\
wisata Di desa
\end{tabular} & & terkait & $\begin{array}{ll}\text { desa } & \text { rendu } \\
\text { tutubadha. } & \\
\end{array}$ \\
\hline
\end{tabular}


Vol. 8 No 2, 2020

\begin{tabular}{|c|c|c|}
\hline & & $\begin{array}{l}\text { koordinasi yang } \\
\text { selalu berjalan ini } \\
\text { menciptkan } \\
\text { harmoni antar } \\
\text { desa dan } \\
\text { pemerntah } \\
\text { kabupaten karena } \\
\text { tidak melanggar } \\
\text { peraturan- } \\
\text { peraturan } \\
\text { ada yang }\end{array}$ \\
\hline & $\begin{array}{l}\text { Menaati peraturan } \\
\text { Desa setempat }\end{array}$ & 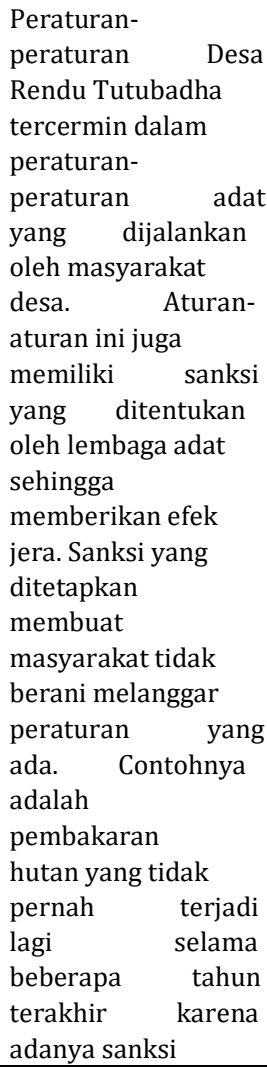 \\
\hline 6 & Menaati peraturan d & setempat \\
\hline & $\begin{array}{l}\text { Pembangunan } \\
\text { perlu mendapat } \\
\text { persetujuan } \\
\text { masyarakat dan } \\
\text { lembaga adat } \\
\text { setempat }\end{array}$ & $\begin{array}{l}\text { Lembaga adat } \\
\text { memegang } \\
\text { peranan dalam } \\
\text { penting } \\
\text { kehidupan } \\
\text { masyarakat Desa } \\
\text { Rendu } \\
\text { Tutubadha. oleh } \\
\text { sebab itu lembaga } \\
\text { adat selalu } \\
\text { dilibatkan dalam } \\
\text { pengambilan } \\
\text { keputusan, dalam } \\
\text { kelompok sadar } \\
\text { wisata lembaga } \\
\text { adat masuk dalam } \\
\text { struktur sebagai } \\
\text { penasihat }\end{array}$ \\
\hline & $\begin{array}{l}\text { Menjalin } \\
\text { komunikasi dan } \\
\text { koordinasi } \\
\text { dengan } \\
\text { masyarakat dan } \\
\text { lembaga }\end{array}$ & $\begin{array}{l}\text { Kooridinasi untuk } \\
\text { pengembangan } \\
\text { objek terus } \\
\text { terjadi. salah satu } \\
\text { contoh paling } \\
\text { sering } \quad \text { terjadi }\end{array}$ \\
\hline
\end{tabular}

\begin{tabular}{|c|c|c|}
\hline & $\begin{array}{l}\text { adat } \\
\text { setempat dalam } \\
\text { pengembangan } \\
\text { objek }\end{array}$ & $\begin{array}{l}\text { adalah ketika ada } \\
\text { tamu dalam } \\
\text { rombongan yang } \\
\text { berkunjung akan } \\
\text { melibatkan } \\
\text { lembaga adat } \\
\text { dalam } \\
\text { pementasan } \\
\text { tarian atau ritual- } \\
\text { ritual adat lain } \\
\end{array}$ \\
\hline \multirow[t]{3}{*}{7} & \multicolumn{2}{|c|}{ Memberikan kepuasan kepada konsumen } \\
\hline & $\begin{array}{l}\text { Menyediakan } \\
\text { fasilitas } \\
\quad \text { dan } \\
\text { memberikan } \\
\text { pelayanan prima } \\
\text { dan memuaskan } \\
\text { kepada } \\
\text { konsumen }\end{array}$ & $\begin{array}{lr}\text { Pelayanan } & \text { yang } \\
\text { prima } & \text { tampak } \\
\text { dalam } & \\
\text { penyambutan } & \\
\text { tamu dengan } \\
\text { tarian } & \text { dan } \\
\text { penyediaan } & \\
\text { konsumsi } & \text { untuk } \\
\text { tamu (tergantung } \\
\text { pesanan), selain } \\
\text { itu tamu yang } \\
\text { datang juga akan } \\
\text { didampingi } \\
\text { langsung oleh staf } \\
\text { pokdarwis }\end{array}$ \\
\hline & $\begin{array}{l}\text { Menyedaikan } \\
\text { media } \\
\text { untuk } \\
\text { memperoleh } \\
\text { umpan balik dari } \\
\text { konsumen }\end{array}$ & $\begin{array}{l}\text { Dalam rangka } \\
\text { memperoleh } \\
\text { umpan balik dari } \\
\text { wisatawan atau } \\
\text { konsumen, } \\
\text { pokdarwis } \\
\text { menyediakan } \\
\text { buku tamu untuk } \\
\text { wisatawan, untuk } \\
\text { dalam buku tamu } \\
\text { tersebut terdapat } \\
\text { bagian kan dan pesan } \\
\text { kesan } \\
\text { dari wisatawan. } \\
\text { kesan dan pesan } \\
\text { ini dijadikan } \\
\text { sebagai ajuan } \\
\text { untuk operasional } \\
\text { wisata di desa. }\end{array}$ \\
\hline \multirow[t]{2}{*}{8} & \multicolumn{2}{|c|}{$\begin{array}{l}\text { Dipasarkan dan dipromosikan dengan jujur dan } \\
\text { akurat sehigga sesuai dengan harapan dan } \\
\text { kenyataan }\end{array}$} \\
\hline & $\begin{array}{lr}\text { Materi } & \\
\text { pemasaran } & \\
\text { harus akurat, } \\
\text { jelas } \\
\text { berkualitas }\end{array}$ & $\begin{array}{l}\text { Kelompok sadar } \\
\text { wisata desa rendu } \\
\text { tutubahda selaku } \\
\text { pengelola Desa } \\
\text { Rendu Tutubadha } \\
\text { belum } \\
\text { menerapkan } \\
\text { strategi } \\
\text { pemasaran dalam } \\
\text { bentuk apapun, } \\
\text { pemasaran } \\
\text { dilakukan secara } \\
\text { mandiri leh } \\
\text { beberapa travel } \\
\text { blogger atau } \\
\text { penggiat } \\
\text { pariwisata }\end{array}$ \\
\hline
\end{tabular}


Vol. 8 No 2, 2020

\begin{tabular}{|c|c|}
\hline & $\begin{array}{l}\text { Kabupaten } \\
\text { Nagekeo }\end{array}$ \\
\hline $\begin{array}{l}\text { Materi } \\
\text { pemasaran yang } \\
\text { jujur dan harus } \\
\text { sesuai dengan } \\
\text { kenyataan }\end{array}$ & $\begin{array}{lr}\text { Promosi } & \text { wisata } \\
\text { yang } & \text { dilakukan } \\
\text { oleh } & \text { travel } \\
\text { blogger } & \text { atau } \\
\text { penggiat } & \\
\text { pariwisata } & \text { di } \\
\text { Kabupaten } & \\
\text { Nagekeo } & \\
\text { umumnya } & \\
\text { berisikan } & \\
\text { pengalaman } & \\
\text { pribadi } & \text { mereka } \\
\text { ketika } & \\
\text { berkunjung } & \\
\text { sehingga } & \\
\text { cenderung } & \text { jujur } \\
\text { dan } & \text { sesuai } \\
\text { dengan kenyataan }\end{array}$ \\
\hline
\end{tabular}

Sumber: Hasil Penelitian, 2018

\section{DAFTAR PUSTAKA.}

Arida, I Nyoman Sukma.2017. Ekowisata (pengembangan, partisipasi lokal, dan tantangan ekowisata). Denpasar : Cakra Press

Bungin, Burhan.2014. Penelitian Kualitatif. Jakarta : Prenada Media Grup

Charles Betomi, Ni Made Oka Karini, dan I Putu Sudana (2015). Pengemasan Paket Ekowisata di Desa Liang Ndara, Kecamatan Mbeliling, Kabupaten Manggarai Barat, Flores, Nusa Tenggara Timur.

Cooper et. Al.1993. Tourism Principles \& Practice. England : Longman Group Limited

Gilang Pamungkas (2013). Kapasitas Jejaring Stakeholder dalam Pengelolaan Ekowisata (Studi Kasus: Taman Nasional Gunung Gede Pangrango)

Kusworo, HA.2000. Pengembangan Wisata Pedesaan Tepi Hutan Berbasis Kerakyatan dalam Pengusahaan Ekowisata, Pengusahaan Ekowisata.Chafid Fandeli, ed. Fakultas kehutanan. Yogyakarta: Universitas Gadjah Mada

M. Nurdin Razak \& Nur Emma Suriani (2011). Pemetaan Potensi Ekowisata di Taman Nasional Baluran. Jurnal Perencanaan Destinasi

\section{KESIMPULAN}

Potensi ekowisata yang terdapat di Desa Rendu Tutubadha terdiri dari potensi alam dan budaya yaitu sumber air panas alami ae petu meze, Gunung Lambo, perkampungan tradisional Rendu Tutubadha, dan ritual etu. Potensi-potensi ini dapat dikembangkan menjadi kegiatan ekowisata seperti trekking dan birdwatching di Gunung Lambo, trekking ke sumber air panas alami ae petu meze. Selain itu, kegiatan ekowisata lain yang dapat dikembangkan adalah mengamati kehidupan masyarakat lokal atau berpartisipasi dalam ritual $e t u$.

Berdasarkan analisis dengan

menggunakan standar the international ecotourism standard disimpulkan bahwa bahwa Desa Rendu Tutubadha cukup siap untuk mengembangkan ekowisata. Peraturan-peraturan adat dan desa yang menjaga keaslian bangunan, kelestarian alam dan kebudayaan menjamin prinsip-prinsip ekowisata dapat berjalan dengan baik. Pembenahan juga perlu dilakukan di beberapa aspek seperti pelatihan guide agar benar-benar paham dengan konsep dan praktik ekowisata, staf kelompok sadar wisata juga perlu dilibatkan agar memiliki perspektif yang sama. Aspek lain yang perlu dibenahi adalah pemasaran, di mana pemasaran selama ini dilakukan oleh pihak lain seperti travel blogger atau penggiat pariwisata. Kelompok sadar wisata Desa Rendu Tutubadha sebagai otoritas atau lembaga yang berwenang perlu melakukan pemasaran agar fungsi kelompok sadar wisata dapat berjalan. 